\title{
Seeing through the eyes of patients with age-related macular degeneration
}

\section{Dear Editor,}

Age-related macular degeneration (AMD) is a severe ocular disease characterised by progressive deterioration of the macula, the most sensitive central part of the retina. ${ }^{1}$ It is the most common cause of irreversible vision loss among individuals aged $\geq 60$ years in developed countries, ${ }^{2}$ and accounts for about $6 \%$ of all causes of blindness worldwide. ${ }^{3}$ A population-based cross-sectional study in Singapore revealed its agestandardised prevalence was $5.1 \%$ (95\% confidence interval [CI] 4.6-5.5) for early AMD and 0.5\% (95\% CI 0.4-0.6) for late AMD. ${ }^{4}$ Given Singapore's rapidly ageing population, the prevalence of AMD among its residents aged $\geq 40$ years is projected to increase by $54 \%$ from 125,274 (95\% CI 123,241-127,307) cases in 2015 to $193,435(190,295-196,575)$ cases in $2040 .{ }^{5}$

Patients with AMD often have relative scotomas and metamorphopsia in their central visual field. The Amsler grid is an inexpensive and rapid test designed to specifically test visual field defects in the central 10 degrees. ${ }^{6}$ Utilising a suprathreshold target to analyse the central vision, it is good for detecting metamorphopsia but is not sensitive for the detection of relative scotomas. ${ }^{7}$ Attempts have been made to characterise the size, shape, slope and extent of scotomas using a 3-dimensional computer-automated threshold Amsler grid test, which may have the potential as a screening tool for the early diagnosis of AMD. ${ }^{8}$

The Snellen visual acuity chart is the most commonly used chart to evaluate vision in clinical practice. In the last few decades, the Early Treatment Diabetic Retinopathy Study chart has become the gold standard test to measure visual acuity and evaluate eyes with macular disease in clinical trials. ${ }^{9}$ However, these tests are non-timed and thus may not simulate real-world situations such as driving, where there is a limited amount of time to recognise objects, read signs and make important vision-based decisions. ${ }^{10}$ This is important for patients with AMD because they find difficulties with many vision tasks that are timedependent such as reading, driving and recognising faces in fluid social situations. ${ }^{11}$

In an effort to realistically depict how AMD patients see themselves in the mirror, one of us (AH), a professional portrait artist, has painted 17 portraits of individuals suffering from varying severities of AMD as seen
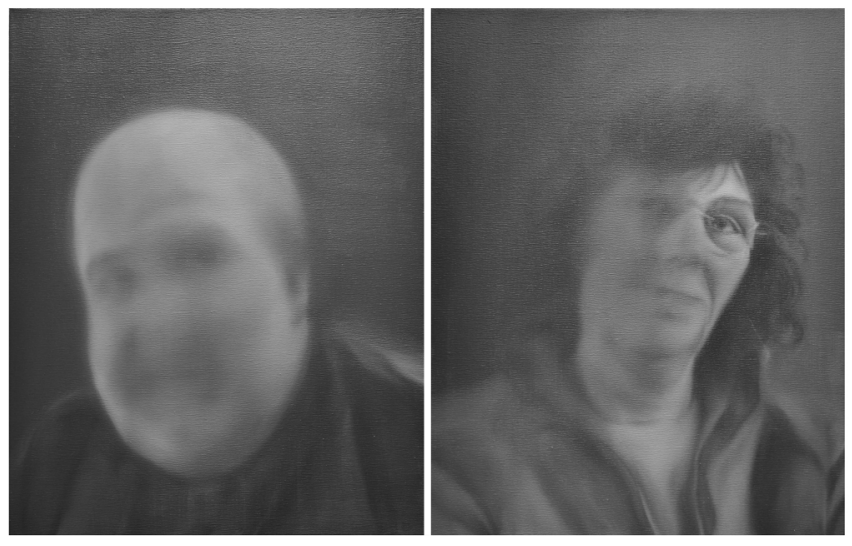

Fig. 1. Two portraits depicting visual abnormalities due to age-related macular degeneration as seen by the patients themselves.

through the patients' own eyes (Fig. 1). The portraits were conceptualised by first obtaining detailed information from an AMD patient on the specific visual abnormalities he or she experienced, such as metamorphopsia and relative scotoma through a face-to-face interview. Based on this information, a photograph of the patient was manipulated to match the patient's perception of himself or herself in the mirror and a preliminary portrait of the patient was sketched. The portrait was then adjusted to reflect more accurately the patient's perception. Re-painting and verification by the patient were repeated several times before the portrait was finalised. Interestingly, we found that AMD patients who had their portraits painted rarely reported image distortion but more often reported scotoma(s).

To showcase these portraits, we organised a unique public art exhibition in conjunction with the AMD Awareness Week campaign in Singapore in 2010. ${ }^{12}$ The exhibition was very well-received and we believe such artworks are useful to raise public awareness of AMD and enable a more accurate perception and understanding of the visual problems experienced by AMD patients in their daily lives. ${ }^{13-15}$

\section{REFERENCES}

1. Au Eong KG. Age-related macular degeneration: an emerging challenge for eye care and public health professionals in the Asia Pacific region. Ann Acad Med Singap 2006;35:133-5.

2. Wagle AM, Au Eong KG. A decade of progress in the understanding, prevention and treatment of age-related macular degeneration in Singapore. Ann Acad Med Singap 2015;44:116-8. 
3. Taylor HR. Global Blindness: The progress we are making and still need to make. Asia Pac J Ophthalmol (Phila) 2019;8:424-8.

4. Cheung CM, Li X, Cheng CY, et al. Prevalence, racial variations, and risk factors of age-related macular degeneration in Singaporean Chinese, Indians, and Malays. Ophthalmology 2014;121:1598-603.

5. Ansah JP, Koh V, de Korne DF, et al. Projection of eye disease burden in Singapore. Ann Acad Med Singap 2018;47:13-28.

6. Amsler M. Earliest symptoms of diseases of the macula. Br J Ophthalmol 1953;37:521-37.

7. Wall M, Sadun AA. Threshold Amsler grid testing: cross-polarizing lenses enhance yield. Arch Ophthalmol 1986;104:520-3.

8. Nazemi PP, Fink W, Lim JI, et al. Scotomas of age-related macular degeneration detected and characterized by means of novel three-dimensional computer-automated visual field test. Retina 2005;25:446-53.

9. Lim LA, Frost NA, Powell RJ, et al. Comparison of the ETDRS logMAR, 'compact reduced logMar' and Snellen charts in routine clinical practice. Eye 2010;24:673-7.

10. Barteselli G, Gomez ML, Doede AL, et al. Visual function assessment in simulated real-life situations in patients with age-related macular degeneration compared to normal subjects. Eye 2014;28:1231-8.

11. Mitchell J, Bradley C. Quality of life in age-related macular degeneration: a review of the literature. Health Qual Life Outcomes 2006;4:97.

12. Wagle AM, How ASH, Bakthavatsalu M, et al. A vision for the nation: a decade of AMD awareness campaign in Singapore. Singapore: Spring Publishing; 2015.
13. Sanjay S, Neo HY, Sangtam T, et al. Survey on the knowledge of age-related macular degeneration and its risk factors among Singapore residents. Clin Exp Ophthalmol 2009;37:795-800.

14. Sanjay S, Chin YC, Teo HT, et al. A follow-up survey on the knowledge of age-related macular degeneration and its risk factors among Singapore residents after 5 years of nation-wide awareness campaigns. Ophthalmic Epidemiol 2014;21:230-6.

15. Woo JH, Au Eong KG. Don't lose sight of age-related macular degeneration: the need for increased awareness in Singapore. Singapore Med J 2008;49:850-3.

Srinivasan Sanjay, ${ }^{1,2}$ MS (Oph) (Bengaluru $)$,

Ajeet Madhav Wagle, ${ }^{1,3}$ FRCS (Edin),

Adam Hahn, ${ }_{B A}$, Kah-Guan Au Eong, ${ }^{1,3}{ }_{F R C S(E d i n)}$

${ }^{1}$ Department of Ophthalmology and Visual Sciences, Khoo Teck Puat Hospital, Singapore

${ }^{2}$ Department of Uvea and Ocular Immunology, Narayana Nethralaya, Bengaluru, India

${ }^{3}$ International Eye Cataract Retina Centre, Mount Elizabeth Medical Centre and Farrer Park Medical Centre, Singapore

${ }^{4}$ St Edward's School, Oxford, United Kingdom

Correspondence: Dr Srinivasan Sanjay, Narayana Nethralaya, 121/C, Chord Road, 1st 'R' Block, Rajajinagar, Bengaluru 560010, India.

Email: sanjaygroup24@gmail.com 